\title{
LIBERDADE DE ASSOCIAÇÃO E $O$ RECESSO NAS SOCIEDADES LIMITADAS
}

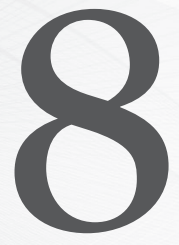

\section{MarLon TOMAZETtE}

Mestre e Doutorando em Direito pelo Centro Universitário de Brasilia. Professor de Direito no Centro Universitário de Brasília - UniCEUB e na Escola Superior do Ministério Público do Distrito Federal e Territórios. Procurador do Distrito Federal. Advogado.

ÁreA do DiReto: Civil; Comercial/Empresarial

Recebido em: 25.07.2011

Aprovado em: 10.08.2011

Resumo: 0 direito de recesso nas sociedades limitadas representa o direito do sócio sair da sociedade, exigindo da própria sociedade o pagamento por suas quotas. Os limites para o exercício desse direito são discutidos pela doutrina, sendo o objetivo do presente trabalho definir quando e em que condições tal direito pode ser exercido. Para tanto, é feita uma análise doutrinária do tema a partir da eficácia horizontal dos direitos fundamentais, em razão do fenômeno da constitucionalização do direito empresarial, tomando-se a liberdade de associação como parâmetro de solução da divergência doutrinária. Dentro dessa análise, são definidas as hipóteses para o direito de recesso nas sociedades por prazo determinado e nas sociedades por prazo indeterminado.

Palavras-chave: Sociedade limitada - Recesso Liberdade de associação.

\begin{abstract}
The dismissal in limited companies is the right of a partner gets out of the partnership, demanding to the partnership itself the payment for their shares. The limits to this right are discussed by the doctrine, with the aim of this study to define when and under what conditions such right can be exercised. For this, there is a doctrinal analysis of the theme from the horizontal effectiveness of fundamental rights, because the phenomena of constitutionalization of business law, taking the freedom of association as a parameter for solving the doctrinal controversy. In this analysis, the hypotheses of dismissal are defined to partnerships for a specific period and to partnerships without specific period.
\end{abstract}

KeYWORDs: Limited company - Dismissal - Freedom of association.

Sumárı: 1. Introdução - 2. 0 surgimento e a importância das sociedades limitadas no Brasil - 3. Natureza das sociedades limitadas - 4. A saída de sócios de uma sociedade limitada: 4.1 Cessão de quotas; 4.20 direito de recesso dos sócios - 5. A constitucionalização do 
direito empresarial como mudança de paradigma interpretativo - 6. A eficácia horizontal dos direitos fundamentais - 7. A eficácia horizontal da liberdade de associação e o direito de recesso: 7.10 direito de recesso nas sociedades limitadas por prazo determinado; 7.20 direito de recesso nas sociedades por prazo indeterminado - 8. Conclusão - 9. Referências.

\section{InTRODUÇÃO}

A formação de sociedades empresárias pressupõe certo grau de consenso entre os sócios, o qual, porém, não inibe o posterior surgimento de conflitos entre os próprios sócios. Tais conflitos são resolvidos normalmente pela saída de um sócio, seja pela cessão de suas quotas, seja pelo exercício do direito de recesso. Neste último ponto, surgem diversas controvérsias na doutrina sobre o limite e a extensão desse direito no atual ordenamento jurídico brasileiro. Dentro dessa ideia, o presente trabalho visa apresentar uma solução para tais divergências, a partir de um enfoque constitucional do assunto.

Não há dúvida de que as sociedades limitadas se difundiram e são fundamentais para o desenvolvimento das atividades empresariais. Assim, o surgimento da controvérsia sobre o direito de recesso em tais sociedades tem dado margem a inúmeros problemas, tanto do ponto de vista teórico quanto do ponto de vista prático, uma vez que tais conflitos são muito comuns. Por isso, a solução dessa controvérsia é de fundamental importância.

Nesse sentido, busca-se um enfoque um pouco diferente do tema, partindo de uma análise constitucional. Inicialmente, deve-se discutir a possibilidade de aplicação dos direitos fundamentais nas relações privadas, como as relações societárias. Reconhecida essa eficácia horizontal direta ou indireta, é certo que os direitos fundamentais influenciam a interpretação das relações privadas, reforçando a ideia da constitucionalização do direito privado. Esse fenômeno já vem sendo bastante estudado, especialmente no que tange à função social da propriedade e aos direitos de personalidade. Contudo, os reflexos da liberdade de associação, consagrada no art. $5 .^{\circ}, \mathrm{XX}$, da CF/1988, nas relações privadas não possuíram ainda a devida análise nessa nova ótica de constitucionalização do direito privado. Neste particular é que se justifica o presente trabalho como análise da incidência deste princípio constitucional da liberdade de associação às relações privadas, mais especificamente, às relações societárias, diretamente ou como meio de conformação das normas infraconstitucionais.

\section{O SURGIMENTO E A IMPORTÂNCIA DAS SOCIEDADES LIMITADAS NO BRASIL}

As atividades econômicas em geral não são desenvolvidas apenas pelas pessoas físicas isoladamente, porquanto nem sempre é possível que elas sozinhas 
exerçam a atividade pretendida. Em muitos casos é necessária a combinação de esforços ou recursos de pessoas para que a atividade pretendida seja exercida da melhor maneira. Em outras palavras, é extremamente frequente a união de pessoas em sociedades para o exercício de atividades econômicas. Francisco Amaral afirma, em relação às pessoas jurídicas como um todo, que:

"Sua razão de ser está na necessidade ou conveniência de as pessoas singulares combinarem recursos de ordem pessoal ou material para a realização de objetivos comuns, que transcendem as possibilidades de cada um dos interessados por ultrapassarem o limite moral da sua existência ou exigirem a prática de atividades não exercitáveis por eles" (AmAral, 2000, p. 271-272).

Dentre os vários tipos de sociedades existentes no ordenamento jurídico brasileiro, merecem especial importância as sociedades limitadas. No Brasil, as sociedades limitadas representam 98,93\% das sociedades constituídas no período de 1985 a 2005. No ano de 2005, elas representaram 98,53\% de todas as sociedades constituídas (fonte: www.dnrc.gov.br). Vê-se, pois, claramente que tal tipo societário vem desempenhando papel fundamental no dia a dia da economia do país. Conquanto não represente tanto investimento quanto às sociedades anônimas, é certo que tal tipo societário desempenha uma posição de destaque na vida econômica do país, sobretudo pelo elevado número de relações nas quais está presente. Essa elevada importância está diretamente relacionada às vantagens oferecidas por tal forma societária.

Até o século XIX, podiam-se dividir as sociedades existentes em dois grupos: as sociedades de pessoas de simples constituição, mas de responsabilidade ilimitada, e as sociedades anônimas de responsabilidade limitada, mas de constituição e funcionamento complexos. Tal situação não era satisfatória para pequenos e médios empresários, na medida em que estes buscavam a responsabilidade limitada, mas sem a complexidade da sociedade anônima. Com a Revolução Industrial impunha-se o preenchimento desse vazio legislativo, a fim de se criar um tipo societário que atendesse aos interesses das pequenas e médias empresas.

No fim do século XIX, em resposta às necessidades de pequenos e médios empresários, surge um novo tipo societário que conjuga as vantagens das sociedades de capitais e das sociedades de pessoas, isto é, assegura aos sócios uma responsabilidade limitada pelas obrigações sociais, sem a complexidade da sociedade anônima (Bulgarelli, 1998, p. 117). Sem maiores formalidades ou complicações e com riscos limitados de prejuízo, é indubitável que esta é a forma mais aconselhável para os pequenos e médios empreendimentos. Essa estrutura que justificou a criação das sociedades limitadas se manteve na sua atual disciplina dada pelo Código Civil. 


\section{NatUREZA dAS SOCIEDAdES limitadAS}

Como visto, a sociedade limitada combina as vantagens de diversos tipos de sociedades e, em razão disso, é difícil seu enquadramento como sociedades de pessoas ou de capitais.

João Eunápio Borges, coerentemente, enquadrava a sociedade limitada como uma sociedade de capitais, porquanto ela não oferece como garantia aos seus credores o patrimônio pessoal dos sócios (1959, p. 56). Todavia, esse é apenas um dos elementos para se verificar a existência de uma sociedade de pessoas ou de capitais. Com efeito, neste particular, a sociedade limitada se aproxima extremamente da sociedade anônima, o que não é suficiente para enquadrá-la como uma sociedade de capitais, na medida em que há também um acentuado caráter pessoal nas relações entre os sócios (FERRARA JR.; CorSI, 1999 , p. 862) que a aproxima da sociedade de pessoas.

Há quem afirme que a limitada é uma sociedade de pessoas pela forma contratual de sua constituição, que obedecia aos arts. 300 a 302 do CCo (MARTins, 1998, p. 272-273). De modo similar, há quem ressalte a natureza personalista afirmando que os sócios podem, sem motivos, impedir a transferência das quotas, ou determinar a dissolução da sociedade pela morte de um deles, denotando uma maior importância da pessoa do sócio (Pontes DE Miranda, 1984, p. 362). No mesmo sentido, há quem também enquadra a limitada como uma sociedade de pessoas, afirmando que a solidariedade entre os sócios para a integralização do capital social fará com que as qualidades pessoais dos sócios sejam determinantes na formação da sociedade (Cristiano, 1998, p. 32-33). Ainda há aqueles que ressaltam a natureza intuitu personae da referida sociedades, afirmando a importância da pessoa dos sócios, em face da sua contribuição para a formação do capital social (Lово, 2004, p. 51; CAMPINHo, 2004, p. 163).

Não obstante a força de tais argumentos, é certo que esse personalismo não estará presente em todas as sociedades limitadas, vale dizer, a liberdade, que é assegurada aos sócios, permitirá a configuração de sociedades eminentemente personalistas, mas também de sociedades eminentemente capitalistas. Rubens Requião, mesmo defendendo a natureza personalista da sociedade limitada, afirma que o "contrato social poderá inculcar-lhe um estilo personalista ou capitalista" (1998, p. 411).

Desse modo, para a maioria da doutrina (Coelho, 2009, p. 362; Bertoldi, 2001, p. 193; Borba, 2003, p. 63; LuCENA, 1997, p. 45; WALD, 2005, p. 309; SIMÃo FILHo, 2004, p. 37; CalÇAS, 2003, p. 29) a sociedade limitada pode ser tida como uma sociedade híbrida, isto é, de acordo com o caso concreto ela poderá ter um caráter de sociedade de pessoas ou de capital. "São os sócios e não a lei 
que a definem. A negociação, traduzida no contrato social, elucida se a limitada será de pessoa ou de capital" (Coelho, 2009, p. 362). Com efeito, impõe-se a análise das cláusulas do contrato social para se saber se na sociedade limitada predomina o caráter personalista ou o caráter capitalista. No regime do Código Civil de 2002, o hibridismo da limitada também é mantido, pois poderão existir sociedades com traços personalistas e com traços capitalistas, dando-se maior ou menor importância à pessoa dos sócios, senão vejamos.

Portanto, diante das várias configurações possíveis da limitada, apenas no caso concreto, à luz das decisões dos sócios em relação a tais matérias, será possível afirmar se a limitada é de pessoas ou de capitais, não se podendo definir a priori a sua natureza. No caso de silêncio dos sócios sobre tais matérias, prevalece a natureza personalista, diante das soluções legais impostas.

\section{A SAÍdA DE SÓCIOS DE UMA SOCIEDADE LIMITADA}

Apesar da discussão quanto à natureza da sociedade limitada, não há dúvida de que ela é constituída por meio de um contrato plurilateral, nos quais é possível distinguir o que diz respeito à adesão de cada parte e o que diz respeito ao contrato como um todo (FERRARA JR.; Corsi, 1999, p. 285). Nada impede que a sociedade seja dissolvida pela saída de algum sócio, mas é possível que a sociedade subsista ante a saída de algum dos sócios. Portanto, é possível continuar a sociedade após a saída de algum sócio, mesmo com a anulação ou nulidade de alguma adesão e mesmo após a morte ou incapacidade de qualquer dos membros.

Assim, a construção do contrato plurilateral permite que se atenda também ao princípio da preservação da empresa, pelo qual, sempre que possível, há que se manter a empresa como organismo econômico produtor de riquezas, tendo em vista os inúmeros interesses envolvidos, como os dos trabalhadores, do fisco e dos consumidores. Ademais, há que se atentar para a função social que a sociedade desempenha, equacionando os interesses da sociedade, dos sócios que saem da sociedade, ou seus herdeiros, e dos sócios que permanecem.

Essa saída de um sócio da sociedade pode se dar de várias formas. Ele pode ceder suas quotas a outros sócios ou a terceiros, não havendo nesse caso uma resolução do contrato, mas apenas uma transferência de posição contratual. Além disso, poderá haver a resolução da sociedade em relação a um sócio, nos casos de morte, exclusão e exercício do direito de recesso. Em todos esses casos de resolução, o vínculo do sócio é dissolvido, mas a sociedade pode subsistir. De todas as hipóteses mencionadas, apenas na cessão de quotas e no recesso há propriamente a iniciativa do sócio e, por isso, somente tais hipóteses serão objeto de análise no presente trabalho. 


\subsection{Cessão de quotas}

Ao subscrever uma quota do capital social, o sócio adquire um direito pessoal de ser sócio e direitos patrimoniais, consistentes na participação nos lucros e no acervo social, em caso de liquidação. Representando direitos, as quotas podem ser cedidas a outras pessoas a título oneroso, ou a título gratuito. Discute-se, contudo, se tal cessão é livre, ou se depende da concordância dos demais sócios.

A legislação original das limitadas não estabelecia nada a respeito, ficando a solução da questão sujeita ao arbítrio dos próprios sócios, que no contrato social podem impor condições para tal cessão. Todavia, no silêncio do contrato social, a cessão é livre ou depende da anuência dos demais sócios? Se depender, basta a maioria ou é necessária a unanimidade? A solução de tal questão passava pela definição da legislação que incidiria supletivamente sobre as sociedades limitadas (Lei das Sociedades Anônimas ou Código Comercial) e pela natureza intuitu personae ou não de tal sociedade, gerando uma grande controvérsia na doutrina.

O Código Civil italiano estabelece a livre cessão das quotas, salvo disposição em contrário do contrato social (Mogorovich, 2003, p. 14). No direito espanhol, é estabelecida a livre cessão entre sócios, ou a familiares dos sócios ou a sociedades integrantes do mesmo grupo, salvo disposição em contrário (Irujo, 2000, p. 17). Para terceiros, a cessão das quotas depende do consentimento da assembleia, salvo se houver disposição no contrato social em sentido diverso. No direito francês, um sócio pode ceder suas quotas livremente para outro sócio. Para terceiros a cessão depende do consentimento de sócios que representem a maioria do capital social (Cozian; Viandier; Deboissy, 2009, p. 470).

O Código Civil de 2002 mantém a possibilidade de os sócios disporem sobre a livre cessão ou não das quotas na sociedade limitada. Há ampla margem de liberdade para os sócios, que podem dar um caráter mais personalista ou mais capitalista à sociedade limitada.

No silêncio do contrato social, a cessão das quotas a quem é sócio pode ocorrer livremente, não dependendo do consentimento dos demais (art. 1.057 do CC/2002). Tal liberdade pode acabar modificando as relações de poder dentro da sociedade. Em função disso, é extremamente frequente e aconselhável que sejam estabelecidos critérios para a cessão das quotas entre sócios, assegurando a manutenção da proporção. Omisso o contrato também no que diz respeito à cessão das quotas a terceiros, ela pode ser feita desde que não haja oposição de sócios que representem 1/4 (25\%) do capital social. Em outros 
termos, a cessão das quotas a terceiros fica condicionada à aprovação, expressa ou tácita, de sócios que representem três quartos do capital social, seguindo o sistema francês e se adequando ao quórum qualificado, exigido para a alteração do contrato social.

A orientação, seguida pelo Código Civil de 2002, soluciona a divergência doutrinária formada no regime do Dec. 3.708/1919. Todavia, a nosso ver, não adota a melhor orientação sobre a matéria, que deveria seguir a linha do Código Civil italiano, que estabelece a livre cessão das quotas, salvo disposição em contrário do contrato social. A liberdade de contratar dos sócios deveria ser prestigiada, só sendo limitada nos casos de disposição expressa no contrato social que denotasse tal vontade.

\subsection{0 direito de recesso dos sócios}

A par da cessão de quotas, também admite-se a saída do sócio por meio do exercício do chamado direito de recesso, que representa a saída do sócio da sociedade por iniciativa própria, recebendo da própria sociedade determinado valor por suas quotas ou ações. Trata-se de um direito societário de natureza potestativa dirigido à extinção da relação societária daquele sócio com a sociedade (FonsECA, 2008, p. 25). No atual regime do Código Civil, surge uma grande controvérsia sobre os limites do exercício desse direito especificamente para a sociedade limitada, uma vez que há apenas um artigo específico sobre o tema (art. 1.077 do CC/2002) cuja aplicação é extremamente discutida.

O referido art. 1.077 do CC/2002 afirma ser possível o recesso nos casos de alteração do contrato social, de fusão ou de incorporação. Em razão disso, alguns autores (Borba, 2003, p. 128; CAlÇAS, 2003, p. 133; Negrão, 2003, p. 370; Carvalhosa, 2003, p. 245-246; Andrade Filho, 2004, p. 233). Para eles, não haveria que se falar em vinculação perpétua nesse caso, porquanto nas sociedades limitadas haveria uma objetivação das participações. Nesse sentido, as hipóteses mencionadas referido artigo seriam entendidas como um rol taxativo.

Numa posição intermediária, Waldo Fazzio Júnior (2003, p. 171) afirma que a solução dependerá da legislação supletiva aplicável à sociedade limitada. Pelo grande número de sociedades limitadas existentes, o capítulo próprio que disciplina essas sociedades nem sempre é suficiente para todos os problemas que surgem. Assim, o art. 1.053 do CC/2002 determina a aplicação supletiva das regras das sociedades simples, mas admite que os sócios definam expressamente como legislação supletiva a lei das sociedades por ações. Dento dessa ideia, o referido autor afirma que, se forem aplicadas su- 
pletivamente as regras das sociedades simples, nesse caso teria lugar o art. 1.029 do CC/2002 que admite o recesso sem motivo nas sociedades por prazo indeterminado; todavia, se for aplicada subsidiariamente a lei das sociedades anônimas, o recesso estaria restringido aos casos legalmente previstos exigindo uma motivação.

Outros autores, por sua vez, limitam a aplicação do art. 1.077 do CC/2002 às sociedades por prazo determinado. Desse modo, eles afirmam que, em se tratando de um contrato por prazo indeterminado, assiste ao contratante o direito de retirada a qualquer momento (LuCENA, 1997, p. 554-555; CAMPINHo, 2004, p. 219; Coelho, 2003, p. 102; Lobo, 2004, p. 231-232; Nerillo, 2004, p. 127).

Há argumentos válidos em todos os sentidos, mas deve-se dar uma solução a esse problema, a fim de dar mais segurança jurídica àqueles que participam de tais sociedades. As discussões sobre tal tema não podem, porém se restringir ao direito empresarial. A transformação material do mundo a partir da segunda metade do século XX também gerou uma transformação do direito, reconhecendo-se mudanças na aplicação do direito empresarial que deve ser interpretado à luz da Constituição Federal.

\section{A CONSTItUCIONALIZAÇÃO DO DIREITO EMPRESARIAL COMO MUDANÇA DE PARADIGMA INTERPRETATIVO}

Como visto, esse problema não pode ser resolvido apenas a luz das normas infraconstitucionais sobre o assunto, ou seja, há que se interpretar a legislação sobre o recesso de modo a realizar os valores princípios e finalidades políticas, sociais e econômicas nos moldes preconizados pela Constituição Federal (AdiERS, 2008, p. 75).

O direito empresarial surgiu em virtude da necessidade de uma regulamentação especial da matéria mercantil, tendo em vista que as características peculiares ao direito civil não se prestavam a atender os fins ligados especificamente ao direito comercial. Lyon-Caen e Renault (1910, p. 3-4) apontam três motivos para a necessidade dessa distinção: há instituições públicas ou privadas que são típicas do comércio, como as bolsas, os bancos e os armazéns gerais; as operações comerciais se realizam em massa e envolvem grandes valores com frequência; e a importância do cumprimento das obrigações. Hamel, Lagarde e Jauffret (1980, p. 9-11) também asseveram três motivos para a existência de um direito comercial autônomo: a necessidade do reforço do crédito, a rapidez das operações comerciais e a necessidade de publicidade. Portanto, a especificidade do direito empresarial repousa basicamente em três pilares: a rapidez, a segurança e o crédito, vale dizer, ele exige um reforço ao crédito, uma discipli- 
na mais célere dos negócios, a tutela da boa-fé e a simplificação da movimentação de valores, tendo em vista a realização de negócios em massa (REINHARD; Chazal, 2001, p. 117).

Essa inegável autonomia do direito empresarial não significa, porém, um total distanciamento de outros ramos do direito, especialmente do direito constitucional. Atualmente, dentro da perspectiva filosófica do pós-positivismo, a Constituição passa a ser não apenas um sistema em si, mas também um modo de olhar e interpretar todos os demais ramos do direito (BARROSO, 2008, p. 253), inclusive o direito empresarial.

A modernidade trouxe consigo um processo de transformação do direito privado, inclusive o direito empresarial, que passou a ser profundamente influenciado por normas constitucionais, afastando ou ao menos mitigando a tradicional dicotomia direito público e direito privado. Atualmente, a Constituição Federal passou a tratar de um número muito maior de matérias, inclusive de aspectos tipicamente tratados pelo direito privado (CostA, 2008, p. 33), como as limitações ao direito de propriedade, acarretando um processo de constitucionalização do direito privado, como consequência inevitável da natureza do Estado Social, sem representar, porém qualquer diminuição à tradição do direito privado (BARroso, 2009, p. 372).

As normas de direito privado devem hoje ser interpretadas de modo a realizar os valores, princípios e finalidades políticas, sociais e econômicas nos moldes preconizados pela Constituição Federal. Há que se reconhecer o valor normativo e a supremacia dos princípios constitucionais na interpretação e aplicação das regras infraconstitucionais. Além disso, deve-se reconhecer que os princípios constitucionais "exercem a função de valores guias e assumem um papel central na articulada pluralidade das fontes do direito, o que exclui que se possa configurar o sistema jurídico dividido em ramos autônomos ou em tantos microssistemas policêntricos, em categorias ou níveis normativos separados e não comunicáveis entre si" (Perlingieri, 2008, p. 2).

A constitucionalização do direito privado pode ser entendida modernamente em dois aspectos. Num primeiro aspecto, a constitucionalização significaria o tratamento constitucional de temas tipicamente privados como a família e a propriedade. Num segundo aspecto, a constitucionalização do direito privado significa a mudança de paradigma hermenêutico, com a aceitação da força normativa dos princípios, a distinção entre princípios e regras e especialmente a interpretação conforme a Constituição (FACCHINI NeTO, 2006, p. 39-40). Essa mudança de enfoque traz os direitos fundamentais para a órbita do direito privado como fatores determinantes na sua aplicação e interpretação. 


\section{A EFICÁCIA HORIZONTAL DOS DIREITOS FUNDAMENTAIS}

Os direitos fundamentais são elementos constitutivos do ordenamento constitucional (HÄBERLE, 2003, p. 7). Eles podem ser conceituados como:

"Normas jurídicas, intimamente ligadas a ideia de dignidade da pessoa humana e de limitação do poder, positivadas no plano constitucional de determinado Estado Democrático de Direito, que, por sua importância axiológica, fundamentam e legitima todo o ordenamento jurídico" (Marmelstein, 2008, p. 20).

Dentro dessa perspectiva de normas constitucionais fundantes do ordenamento jurídico, os direitos fundamentais devem ser utilizados para solução de conflitos privados. Assim sendo, ganha relevância a liberdade de associação enquanto parâmetro de interpretação das normas infraconstitucionais ligadas à entrada e saída de sócios. Para interpretar um conflito societário à luz da liberdade de associação constitucionalmente prevista como um direito fundamental, deve-se analisar previamente a possibilidade de aplicação de tal direito fundamental às relações privadas, como as relações que se travam em uma sociedade limitada.

Nos Estados Unidos, prevalece a state action doctrine, isto é, os direitos fundamentais impõem limitações apenas às ações estatais. Nesta perspectiva, os direitos fundamentais só seriam aplicáveis nas relações privadas, quando os particulares agirem no exercício de uma atividade tipicamente estatal. Os defensores dessa ideia (DrAY, 1999, p. 145), afirma que os direitos fundamentais são primariamente direitos de defesa contra o Estado, não vinculando entidades privadas. Embora a visão original dos direitos fundamentais tenha sido esta, não é mais possível, ao menos no ordenamento jurídico brasileiro, limitar essa eficácia dos direitos fundamentais a relações com o Estado.

A questão que surge é que nas relações privadas há dois (ou mais) titulares de direitos fundamentais e, por isso, não se pode dar o mesmo tratamento que se dá as relações em face do Poder Público. Apesar disso, a supremacia da Constituição e o caráter objetivo dos direitos fundamentais impõem sua aplicação nas relações entre particulares (Piva, 2009, p. 43; Monteiro; Neuner; Sarlet, 2007, p. 121; Canotilho, 2008, p. 192; Dimoulis; Martins, 2008, p. 113; Alexy, 1993, p. 510-511), vale dizer, um particular pode afirmar o seu direito em relação a outro, consideradas as particularidades da situação concreta e eventual colisão de direitos. De fato, é bem mais fácil visualizar os direitos fundamentais numa relação jurídica de um titular de um direito fundamental em face do Estado. Apesar disso, não há motivo para tal tipo de restrição no direito brasileiro.

Reconhecida a eficácia horizontal dos direitos fundamentais, discute-se ainda se essa eficácia seria direta, independentemente de intervenção do legislador, ou indireta, de acordo com a intervenção do legislador. 
No direito alemão (CANARIS, 2003, p. 54), prevalece a opinião de que tal aplicação deveria ser apenas mediata, isto é, os direitos fundamentais poderiam ser aplicados nas relações privadas a partir da intermediação do legislador. Nesta linha de entendimento, os direitos fundamentais só seriam aplicados a relações privadas depois de serem objeto de regulação pelas normas editadas pelo legislador. A grande justificativa dessa tese é a proteção a autonomia privada e do próprio direito privado.

No direito brasileiro, porém, prevalece a opinião da eficácia direta e imediata dos direitos fundamentais, sobretudo em razão do disposto no art. 5. ${ }^{\circ}$, $\S 1^{\circ}{ }^{\circ}$, da CF/1988 (Monteiro; Neuner; Sarlet, 2007, p. 125; Pessoa, 2009, p. 135). Nesse sentido, o STF já decidiu que ampla defesa e o contraditório seriam garantias aplicáveis ao processo de exclusão de um associado da União Brasileira de Compositores. ${ }^{1}$ Tal concepção não nega a importância da atuação do legislador na concretização dos direitos fundamentais, mas apenas deixa de exigir tal intervenção para a aplicação dos referidos direitos.

Assim, apesar de inúmeras divergências, mais uma vez pela supremacia da Constituição, deve-se concluir pela aplicação direta das normas constitucionais às relações privadas, particularmente de dois modos:

(a) quando inexistir norma infraconstitucional, o juiz extrairá da norma constitucional todo o conteúdo necessário para a resolução do conflito;

(b) quando a matéria for objeto de norma infraconstitucional, esta deverá ser interpretada em conformidade com as normas constitucionais (NETTO LôBO, 2008, p. 21).

Em suma, as normas constitucionais sempre serão aplicadas a relações privadas diretamente ou como meio de conformação das normas infraconstitucionais. Essa aplicação direta dos direitos fundamentais deve ser reconhecida, em razão da supremacia constitucional e da superioridade das normas constitucionais dentro do ordenamento jurídico.

\section{A EFICÁCIA HORIZONTAL DA LIBERDADE DE ASSOCIAÇÃO E O DIREITO DE RECESSO}

Dentre os direitos fundamentais aplicáveis às relações privadas, merece especial atenção a chamada liberdade de associação que poderá ser o parâmetro de solução da controvérsia sobre o direito de recesso nas limitadas. A liberdade

1. STF, RE 201819/RJ, 2. a T., j. 11.10.2005, rel. Min. Ellen Gracie, rel. p/ acórdão Min. Gilmar Mendes, DJ 27.10.2006. 
de associação assegura aos destinatários, pessoas físicas ou jurídicas (SARLET, 2009, p. 222; Branco; Coelho; Mendes, 2008, p. 261), o direito de não ser compelido a associar-se ou a permanecer associado (art. $5 .^{\circ}, \mathrm{XX}$, da CF/1988). Essa liberdade de associação abrange tanto as associações em sentido estrito, como as sociedades, vale dizer, a liberdade de associação diz respeito a qualquer associação de pessoas.

Consagrada constitucionalmente, a liberdade de associação abrange o direito de constituir associações ou sociedades, de ingressar e participar nas associações já constituídas, o direito de não se associar e sair da associação e o direito de auto-organizar-se e desenvolver a atividade associativa (SALVADOR CORDECH, 1997, p. 100-101). Para Jorge Miranda (1998, p. 419-420), a liberdade de associação seria um direito complexo, abrangendo o direito de constituir associações, o direito de não ser coagido a ingressar em uma associação, a pagar contribuições ou de permanecer vinculado à associação. O mesmo autor afirma que ela representa também o direito de deliberar a dissolução da associação, o direito de auto-organização, de livre formação dos seus órgãos, o direito de livre prossecução dos seus fins, o direito de submeter-se a personificação e ainda a proteção contra intervenções arbitrárias do poder político.

À luz do conteúdo desse direito fundamental, vê-se que essa liberdade revela-se como um limite a atuação estatal, isto é, revela-se como um direito de defesa que visa a impedir interferências ilegítimas do Poder Público, seja por meio do Executivo, do Legislativo e do Judiciário. Os direitos fundamentais, como a liberdade de associação, são cânones da legislação (JimENEz CAMPO, 1999, p. 66), vale dizer, representam limites para a formulação de regras.

De outro lado, há que se reconhecer também a liberdade de associação como limitadora da autonomia privada, na medida em que representa um direito fundamental de liberdade aplicado às relações entre particulares. Neste momento, a tutela da autonomia privada não é suficiente para proteger a dignidade da pessoa humana em sociedade desiguais como a nossa (MoraIs, 2008 , p. 39). Dentro dessa perspectiva, a liberdade de associação constitucionalmente assegurada pelo art. $5 .^{\circ}, \mathrm{XX}, \mathrm{da} \mathrm{CF} / 1988$ deverá ser usada como fonte de solução das controvérsias atinentes às relações privadas societárias.

Reconhecida a importância da Constituição para o direito privado em especial para o empresarial, bem como a eficácia direta dos direitos fundamentais nas relações privadas, pode-se resolver a controvérsia sobre o direito de recesso. Especificamente para o direito de recesso, Sérgio Botrel (2009, p. 112) afirma que:

"A partir do momento em que se admite a finalidade do direito privado é concretizar e/ou conciliar a realização dos direitos fundamentais, o direito 
de recesso há que ser interpretado como um mecanismo de concretização do direito fundamental de não permanecer associado (direito da livre associação)."

Assim, é a partir da eficácia horizontal da liberdade de associação, que deve ser interpretação o direito de recesso nas sociedades limitadas. O recesso representaria um corolário do direito fundamental da liberdade de associação, aplicável diretamente às relações privadas, e deve ser interpretado dessa forma. Nesta perspectiva, se o direito de recesso é um direito fundamental ele não pode ser impedido pelo legislador, mas pode ser restringido, desde que sejam obedecidos os limites dos limites, vale dizer, deve ser resguardado o núcleo essencial do direito, não devem ser admitidas limitações casuísticas, as restrições devem ser claras e devem obedecer ao princípio da proporcionalidade (Mendes, 1998, p. 33).

Resta, portanto, saber qual interpretação do direito de recesso é compatível com os limites que podem ser impostos a um direito fundamental. Não se pretende, de nenhum modo, afirmar que tal direito é um direito absoluto não sujeito a limites. Pelo contrário, quer-se reconhecer nesse direito um direito limitado. Porém, esses limites não podem prejudicar o núcleo essencial da liberdade de associação (Alexy, 1993, p. 267).

Tomando-se o parâmetro do direito estrangeiro, a princípio, seria possível concluir pela interpretação restritiva do referido direito. No direito italiano, as hipóteses de recesso limitam-se aos casos de mudança do objeto social, mudança do tipo societário e transferência da sociedade para o exterior (BuONOCORE, 2003, p. 179). No direito português, a retirada só pode ocorrer nos casos de aumento do capital a subscrever total ou parcialmente por terceiros, mudança do objeto, prorrogação da sociedade e transferência da sede da sociedade para o exterior (FurTADO, 2000, p. 485-486). No direito espanhol, a retirada é possível nos casos de alteração do contrato social (alteração do objeto, mudança de domicílio, mudança do regime de transmissão das quotas), ou modificações estruturais (transformação em outro tipo societário, ou prorrogação da duração) (Irujo, 2000, p. 14).

Todavia, essa visão é limitada, tendo em vista a perspectiva constitucional que deve ser dada ao problema. A liberdade de associação indiscutivelmente assegura as pessoas físicas e jurídicas o direito de não permanecer associado. Dentro dessa ideia, o núcleo essencial do direito é o direito de não ficar preso a uma associação, contra sua vontade. Proteger esse núcleo essencial é que deve dar os parâmetros para a solução dessa controvérsia sobre o direito de recesso. Neste particular será oportuno dividir as sociedades limitadas por prazo determinado, das sociedades por prazo indeterminado. 


\subsection{O direito de recesso nas sociedades limitadas por prazo determinado}

Embora não sejam tão frequentes, as sociedades por prazo determinado tem ganhado importância em razão do surgimento de sociedades de propósito específico (SPE). O art. 981 do CC/2002 admite que uma sociedade se restrinja a uma ou mais atividades, dando margem ao que se convencionou denominar de Sociedade de Propósito Específico (SPE), também conhecida como Special Purpose Company (SPC) que pode ser entendida como uma sociedade que se destina a um objeto específico e determinado. Após o advento da Lei 11.079/2004, é comum a aplicação de uma SPE no âmbito das Parcerias Público-Privadas (PPP). Entretanto, a sua colocação não se resume a isso, de sorte que uma SPE pode servir também de instrumento nas operações de recuperação judicial de empresas e de securitização de créditos, além do que os editais de licitação que permitem a participação de consórcios podem exigir a constituição de uma SPE para a assinatura do contrato.

Neste caso, o próprio sócio ao ingressar na sociedade sabe em que limites ele terá que ficar vinculado, isto é, as condições de sua permanência já são conhecidas. Assim sendo, não há motivo para ampliar o direito de recesso nestas sociedades, isto é, o direito de recesso deve ficar restrito às hipóteses já definidas pelo legislador no art. 1.077 do CC/2002, a saber, alteração do contrato social, fusão e incorporação. Apenas nesses casos, haveria uma quebra da legítima expectativa dos sócios e, por isso, lhes seria dada a possibilidade de sair da sociedade.

Nem é preciso recorrer à figura da renúncia a direitos fundamentais, mas mesmo nesta perspectiva, essa interpretação é a mais adequada. Não se pode admitir a renúncia ao direito em si, mas a renúncia ao exercício do direito fundamental vem sendo admitida em algumas situações, desde que a renúncia seja feita pelo titular do direito, de forma voluntária no exercício da autonomia da vontade para um determinado caso concreto e por um período delimitado de tempo. Há casos em que se deve impedir ao menos temporariamente a retirada para evitar ônus excessivo para a sociedade em uma face de estabilização da sua atividade. Nesses casos, a renúncia livremente manifestada poderá ser considerada legítima, desde que não afete o núcleo essencial do direito (ANDRADE, 2009 , p. 296) e não se mostre excessiva, à luz do princípio da proporcionalidade. Esse é o caso das sociedades por prazo determinado.

\subsection{O direito de recesso nas sociedades por prazo indeterminado}

De outro lado, a interpretação da questão para as sociedades por prazo indeterminado não deve ser a mesma. Aqui, não há uma definição prévia da 
duração do vínculo societário, porquanto a sociedade não tem data para ser dissolvida. Pode ocorrer que a sociedade seja extinta rapidamente, mas ela também pode ter uma duração superior à vida de seus sócios pessoas físicas. Tais possibilidades demonstram a impossibilidade de se dar o mesmo tratamento atribuído às sociedades por prazo determinado.

A interpretação da questão poderia ser feita sob a ótica contratual, concluindo-se pela possibilidade de denúncia do contrato a qualquer tempo, em razão da própria natureza plurilateral do contrato. Todavia, a previsão do art. 1.077 do CC/2002 que limita as hipóteses de recesso torna a interpretação exclusivamente contratual difícil de ser sustentada. Assim, sendo deve-se partir para a interpretação conforme a Constituição nesse assunto.

Dentro dessa perspectiva, é oportuno relembrar que os direitos fundamentais impõem ao estado uma competência negativa, evitando que por meio de medidas legislativas se extinga o efetivo exercício do direito fundamental. A liberdade de associação pode ser restringida, desde que obedecidos certos limites, vale dizer, deve ser resguardado o núcleo essencial do direito, não devem ser admitidas limitações casuísticas, as restrições devem ser claras e devem obedecer ao princípio da proporcionalidade (MENDES, 1998, p. 33). É sob esta ótica que deve ser apreciada a constitucionalidade das limitações legais ao exercício do direito de recesso.

Nesse sentido, deve-se concluir a atual legislação brasileira sobre o recesso não pode ser interpretada literalmente, limitando a saída do sócio, exclusivamente, aos casos legalmente previstos no art. 1.077 do CC/2002, embora seja essa uma tendência do direito estrangeiro. Tal interpretação literal significaria a vinculação de um sócio por toda a vida a uma sociedade, desde que não haja mudança contratual, incorporação ou fusão. Em outras palavras, limitar o recesso a tais hipóteses afeta o núcleo essencial desse direito, na medida em que seria bem comum essa vinculação vitalícia à sociedade. Por isso, nas sociedades por prazo indeterminado, deve-se admitir o recesso independentemente de motivação.

A situação do direito de retirada na Lei das Sociedades por Ações não afeta tal conclusão. Nas sociedades anônimas, efetivamente, o direito de retirada é restringido, mas há indiscutivelmente o direito à livre negociação das ações. Mais que isso, nas sociedades anônimas fechadas de natureza familiar, nas quais há uma sociedade de pessoas, tem sido admitida a dissolução parcial independentemente de motivação, ${ }^{2}$ nos mesmos moldes aqui propugnados para o direito de recesso.

2. STJ, EREsp 111294/PR, 2. Seção, j. 28.06.2006, rel. Min. Castro Filho, DJ 10.09.2007. 
Portanto, nas sociedades limitadas por prazo indeterminado, o sócio pode se retirar a qualquer tempo, independentemente de causa justificada, de modo a evitar que o sócio fique indefinidamente preso a sociedade. Trata-se de uma interpretação de tal direito de acordo com a liberdade de associação prevista no art. 5. ${ }^{\circ}, \mathrm{XX}, \mathrm{da} \mathrm{CF} / 1988$. Protege-se, nesta concepção, o núcleo essencial da referida liberdade, evitando uma vinculação vitalícia a uma sociedade.

\section{ConclusÃo}

O direito de recesso nas sociedades limitadas deve ser interpretado à luz da liberdade de associação constitucionalmente assegurada. Trata-se da necessária utilização da Constituição Federal para a interpretação e aplicação do direito privado, em especial o empresarial. Tal fenômeno representa o reconhecimento da supremacia do texto constitucional para toda a aplicação do Direito.

Assim sendo, deve-se buscar garantir aos sócios independentemente da legislação o direito de não ficar preso indefinidamente à sociedade, resguardando o núcleo essencial da referida liberdade. Neste sentido, cogita-se da eficácia horizontal imediata dos direitos fundamentais às relações privadas, em especial as relações societárias. A eventual ausência de legislação não pode impedir a concretização dos valores consagrados na Constituição, em especial dos direitos fundamentais.

Do mesmo modo, deve-se interpretar a legislação atinente ao referido tema, de modo também a evitar uma vinculação vitalícia dos sócios a uma sociedade. Neste particular, ganha destaque outro aspecto dos direitos fundamentais, a sua eficácia negativa enquanto limitadora da atuação legislativa do Estado. Não se pretende em nenhum momento atribuir a qualquer direito fundamental a natureza de um direito absoluto, mas conformas a sua disciplina à proteção dos valores constitucionalmente assegurados.

Dentro dessa perspectiva, deve-se reconhecer que nas sociedades limitadas por prazo determinado, o direito de recesso deverá se limitar às hipóteses previstas no art. 1.077 do CC/2002. A ciência e a atuação do próprio sócio na definição dos limites temporais de sua vinculação à sociedade devem ser considerados suficientes para afirmar que não há prejuízo ao núcleo essencial da referida liberdade de associação. Ademais, ainda que se entenda tal vinculação como uma renúncia ao exercício da referida liberdade, tal renúncia é perfeitamente legítima, na medida em que também não afeta o núcleo essencial desse direito.

Por fim, nas sociedades por prazo indeterminado deve-se reconhecer a possibilidade de recesso imotivado, não exclusivamente por uma questão con- 
tratual, mas especialmente para resguardar o núcleo essencial da liberdade de associação. Limitar o recesso dos sócios aos casos especificamente previstos no Código Civil acaba por ferir a referida liberdade, na medida em que existirão diversos casos de vínculo societário vitalício. Assim, deve-se permitir o recesso sem motivação, para que ninguém seja compelido a permanecer associado.

\section{REFERÊNCIAS}

Adiers, Moacir. Constitucionalização do direito civil: um antigo tema novo. In: Teixeira, Anderson Vichinkeski; Longo, Luís Antonio (coords.). A constitucionalização do direito. Porto Alegre: Sergio Antonio Fabris Ed., 2008.

Alexy, Robert. Teoria de los derechos fundamentales. Madrid: Centro de Estudos Constitucionales, 1993.

Amaral, Francisco. Direito civil: introdução. 3. ed. Rio de Janeiro: Renovar, 2000.

ANDRAde, José Carlos Vieira. Os direitos fundamentais na Constituição portuguesa de 1976. 4. ed. Coimbra: Almedina, 2009.

Andrade Filho, Edmar Oliveira. Sociedade de responsabilidade limitada. São Paulo: Quartier Latin, 2004.

BARroso, Luís Roberto. A constitucionalização do direito e o direito civil. In: Tepedino, Gustavo (org.). Direito civil contemporâneo: novos problemas à luz da legalidade constitucional. São Paulo: Atlas, 2008.

Curso de direito constitucional contemporâneo - Os conceitos fundamentais e a construção do novo modelo. São Paulo: Saraiva, 2009.

Bertoldi, Marcelo M. Curso avançado de direito comercial. São Paulo: Ed. RT, 2001. vol. 1.

Borba, José Edwaldo Tavares. Direito societário. 8. ed. Rio de Janeiro: Renovar, 2003.

Borges, João Eunápio. Curso de direito comercial terrestre. Rio de Janeiro: Forense, 1959. vol. 2.

Botrel, Sérgio. Direito societário constitucional. São Paulo: Saraiva, 2009.

Branco, Paulo Gustavo Gonet; Coelho, Inocêncio M.; Mendes, Gilmar Ferreira. Curso de direito constitucional. São Paulo: Saraiva, 2008.

Brasil. Ministério do Desenvolvimento, Indústria e Comércio Exterior. Estatísticas. Disponível em: [www.dnrc.gov.br].

Bulgarelli, Waldírio. Sociedades comerciais. 7. ed. São Paulo: Atlas, 1998.

BuONOCORE, Vincenzo. La societá a responsabilitá limitata. In: ; BASSI, Amedeo; Pescatore, Salvatore (coords.). La riforma del diritto societário. Torino: Giappichelli, 2003.

Calças, Manoel Queiroz Pereira. Sociedade limitada no Código Civil de 2002. São Paulo: Atlas, 2003. 
Campinho, Sérgio. O direito de empresa à luz do novo Código Civil. 4. ed. Rio de Janeiro: Renovar, 2004.

Canaris, Claus-Wilhelm. Direitos fundamentais e direito privado. Trad. Ingo Wolfgang Sarlet e Paulo Mota Pinto. Coimbra: Almedina, 2003.

Canotilho, José Joaquim Gomes. Estudos sobre direitos fundamentais. São Paulo: Ed. RT, 2008.

Carvalhosa, Modesto. Comentários ao Código Civil. São Paulo: Saraiva, 2003. vol. 13.

Coelho, Fábio Ulhoa. Curso de direito comercial. 13. ed. São Paulo: Saraiva, 2009. vol. 2. . A sociedade limitada no novo Código Civil. São Paulo: Saraiva, 2003.

Costa, Nelson Nery. Direito civil constitucional brasileiro. Rio de Janeiro: Forense, 2008.

Cozian, Maurice; Viandier; Alain; Deboissy, Florence. Droit des sociétés. 22. ed. Paris: Litec, 2009.

Cristiano, Romano. Sociedade limitada no Brasil. São Paulo: Malheiros, 1998.

Dimoulis, Dimitri; Martins, Leonardo. Teoria geral dos direitos fundamentais. São Paulo: Ed. RT, 2008.

DraY, Guilherme Machado. O princípio da igualdade no direito do trabalho. Coimbra: Almedina, 1999.

Facchini Neto, Eugênio. Reflexões histórico-evolutivas sobre a constitucionalização do direito privado. In: SARLET, Ingo Wolfgang (org.). Constituição, direitos fundamentais e direito privado. 2. ed. Porto Alegre: Livraria do Advogado, 2006.

FAzzio Jr., Waldo. Sociedades limitadas. São Paulo: Atlas, 2003.

Ferrara Jr., Francesco; Corsi, Francesco. Gli imprenditori e le societá. 11. ed. Milano: Giuffrè, 1999.

Fonseca, Tiago Soares da. O direito de exoneração do sócio no Código das sociedades comerciais. Coimbra: Almedina, 2008.

Furtado, Jorge Henrique Pinto. Curso de direito das sociedades. 3. ed. Coimbra: Almedina, 2000.

HÄBERLE, Peter. La garantia del contenido essencial de los derechos fundamentales. Madrid: Dykinson, 2003.

Hamel, J.; Lagarde, G.; Jauffret, A. Droit commercial. 2. ed. Paris: Dalloz, 1980. vol. $1, \mathrm{t} .1$.

Irujo, José Miguel Embrid. La sociedad de responsabilidad limitada. In: BROSETA Pont, Manuel. Manual de derecho mercantil. 10. ed. Madrid: Tecnos, 2000.

Jimenez Campo, Javier. Derechos fundamentales: concepto y garantías. Madri: Trotta, 1999.

Loво, Jorge. Sociedades limitadas. Rio de Janeiro: Forense, 2004. vol. 1. 
Lucena, José Waldecy. Das sociedades por quotas de responsabilidade limitada. 2. ed. Rio de Janeiro: Renovar, 1997.

Lyon-Caen, Ch.; Renault, L. Manuel du droit commercial. 10. ed. Paris: Librairie Générale du Droit et de Jurisprudence, 1910.

Marmelstein, George. Curso de direitos fundamentais. São Paulo: Atlas, 2008.

Martins, Fran. Curso de direito comercial. 22. ed. Rio de Janeiro: Forense, 1998.

Mendes, Gilmar Ferreira. Direitos fundamentais e controle de constitucionalidade: estudos de direito constitucional. São Paulo: Celso Bastos Editor - Instituto Brasileiro de Direito Constitucional, 1998.

Miranda, Jorge. Manual de direito constitucional. 2. ed. Coimbra: Coimbra Ed., 1998. vol. IV.

Mogorovich, Sergio. La società a responsabilità limitata. Roma: Buffetti, 2003.

Monteiro, Antonio Pinto; Neuner, Jörg; Sarlet, Ingo Wolfgang (orgs.). Direitos fundamentais e direito privado: uma perspectiva de direito comparado. Coimbra: Almedina, 2007.

Morais, Maria Celina Bodin de. Perspectivas a partir do direito civil-constitucional. In: Tepedino, Gustavo (org.). Direito civil contemporâneo: novos problemas à luz da legalidade constitucional. São Paulo: Atlas, 2008.

Negrão, Ricardo. Manual de direito comercial e de empresa. São Paulo: Saraiva, 2003. vol. 1.

Nerillo, Lucíola Fabrete Lopes. Manual da sociedade limitada no novo Código Civil. Curitiba: Juruá, 2004.

Netto LôBo, Paulo Luiz. A constitucionalização do direito civil brasileiro. In: Tepedino, Gustavo (org.). Direito civil contemporâneo: novos problemas à luz da legalidade constitucional. São Paulo: Atlas, 2008.

Perlingieri, Pietro. A doutrina do direito civil na legalidade constitucional. In: Tepedino, Gustavo (org.). Direito civil contemporâneo: novos problemas à luz da legalidade constitucional. São Paulo: Atlas, 2008.

Pessoa, Luíza Nívea Dias. Eficácia horizontal dos direitos fundamentais no campo material e processual. In: MatıAs, João Luís Nogueira (org.). Neoconstitucionalismo e direitos fundamentais. São Paulo: Atlas, 2009.

Piva, Otávio. Comentários ao art. 5. ${ }^{\circ}$ da Constituição Federal de 1988 e teoria dos direitos fundamentais. 3. ed. São Paulo: Método, 2009.

Pontes de Miranda, Francisco Cavalcanti. Tratado de direito privado. 3. ed. São Paulo: Ed. RT, 1984. vol. 49.

Reinhard, Yves; Chazal, Jean-Pascal. Droit commercial. 6. ed. Paris: Litec, 2001.

Requĩ̃o, Rubens. Curso de direito comercial. 23. ed. São Paulo: Saraiva, 1998. vol. 1.

Salvador Cordech, Pablo (coord.). Asociaciones, derechos fundamentales y autonomia privada. Madri: Civitas, 1997. 
SARLEt, Ingo Wolfgang. A eficácia dos direitos fundamentais. 10. ed. Porto Alegre: Livraria do Advogado, 2009.

Simão Filho, Adalberto. A nova sociedade limitada. Barueri: Manole, 2004.

VAleri, Giuseppe. Manuale di diritto commerciale. Firenze: Casa Editrice Dottore Carlo Cya, 1950. vol. 1.

Wald, Arnoldo. Comentários ao novo Código Civil. Rio de Janeiro: Forense, 2005. vol. XIV.

\section{Pesouisas do Editorial}

\section{Veja também Doutrina}

- A proteção dos acionistas minoritários na alienação do controle de companhias abertas, de Alexandre Wald - RDB 34/345;

- A tutela jurídica do acionista minoritário. De acordo com a Lei 10.303/2001, de Ecio Perin Junior - RDPriv 12/106;

- Aspectos societários do resgate de ações, de Luís Loria Flaks - RDB 15/128;

- Da inexistência do direito de recesso, de Arnoldo Wald - RDB 9/215;

- Inaplicabilidade do art. 137 da Lei das S.A. (Amicus curiae - Consoante o disposto no art. 31 da Lei 6.385/76), de Danilo Alves Corrêa Filho - RDB 31/159; e

- Limitação ao direito de recesso no curso do processo de recuperação judicial de sociedade anônima, de Fernanda Medina Pantoja - RT 857/54. 